\title{
Equal access, (Un)equal uptake: a longitudinal study of cataract surgery uptake in older people in England
}

\author{
Jennifer Whillans ${ }^{*}$ and James Nazroo
}

\begin{abstract}
Background: Uptake of cataract removal is a function of the effectiveness of the healthcare delivery services: services that are inaccessible, inappropriate, or unaffordable will not be utilised by (sub)populations, who consequently live with untreated cataracts. The aim of the study was to identify the relationship between individual wealth inequalities and uptake of cataract surgery in England, having controlled for the effects of potentially confounding variables.
\end{abstract}

Methods: The final sample comprised of 2091 respondents from the English Longitudinal Study on Ageing (ELSA) who were diagnosed with cataracts prior to or during the study, aged 50 and over at wave 1, who had not undergone cataract surgery prior to the first survey observation, and had also provided a response in the second wave of the study. The uptake of cataract surgery was measured using the question, have you ever had cataract surgery? Data from waves 1-5 were used to identify those having received treatment during the 8-year observation window of ELSA. Survival analysis techniques were used.

Results: Having controlled for the effects of potentially confounding variables, wealth did not make a statistically significant contribution to the overall fit of the Cox proportional hazard model nor were individual parameters statistically significant. Thus, respondents' socioeconomic position was not found to be a significant predictor in the uptake of cataract surgery in the UK. Receiving a recommendation from a medical professional was a key driving factors in the uptake of cataract surgery.

Conclusions: Study findings suggest that uptake of cataract surgery among over 50 s with a cataracts diagnosis in England do not discriminate on the grounds of individuals' material social position (wealth).

Keywords: Wealth, Social position, National Health Service (NHS), Visual impairment

\section{Background}

Cataracts remain the leading cause of visual impairment among older people worldwide [1]. Surgical removal of the cataract with intraocular lens implantation remains the only effective treatment available to restore or maintain vision [1-4]. In England, cataract surgery is the most common elective surgical procedure performed under the publically-funded National Health Service (NHS). The uptake of treatment by those who need or are eligible for surgery is argued to be a function of the effectiveness of the

\footnotetext{
*Correspondence: Jennifer.Whillans@manchester.ac.uk

The Cathie Marsh Institute for Social Research (CMlst), School of Social

Sciences, University of Manchester, Humanities Bridgeford Street, Manchester
} M13 9PL, UK

healthcare delivery services: services that are inaccessible, inappropriate, or unaffordable will not be utilised by (sub)populations, who consequently live with untreated cataracts [5].

The picture of inequities in utilisation of medical care is not clear [6,7]. Some research suggests that health care utilisation in the general population in the UK is relatively equitable $[7,8]$, while a number of other macro-studies of utilization (measuring the use of all NHS services) and micro-studies (studying the use of particular services or treatments) indicate inequality, with access to specialist services on the NHS being pro-rich $[7,9,10]$. Reconciling findings may also be challenging as some studies approach socio-economic inequalities in access to care and treatment 
using individual-level characteristics (in terms of income, education, and economic activity) while others use geographic variables (index of multiple deprivation (IMD)). Where cataract surgery uptake is the specific focus of enquiry, Kennan et al. have argued that the rate of cataract surgery by local authority showed a positive correlation with the index of multiple deprivation (IMD) such that the greater the deprivation in an area, the higher the rate of cataract surgery [11]; this suggests that, under the NHS, access to care seems not to be significantly compromised in socially deprived local authorities. This finding does not take into account other socioeconomic factors that may be influencing these observed gradients [12], and is based on aggregate, geographical data rather than individual markers of need. Using longitudinal data and survival analysis techniques, this study aims to identify whether individual wealth inequalities lead to an unequal uptake of cataract surgery among older people in England, having controlled for the effects of other socioeconomic and medically relevant factors.

\section{Methods}

The English Longitudinal Study of Ageing (ELSA) contains detailed information on the health, economic, and social circumstances of older people in England [13] in order that the effects of social, behavioural, and economic factors upon age-related changes in the health and wellbeing of older people can be assessed. The core sample was initially drawn from households that had previously responded to the Health Survey for England (HSE) in 1998, 1999, or 2001 and that were aged 50 and over at the beginning of the data collection period. Five waves of data have been collected to date, beginning in 2002, and collected at 2-year intervals. ELSA contains information on the uptake of cataract surgery irrespective of whether it was carried out under publicallyfunded or private care, providing a complete picture of access to cataract surgery. This study involved the analysis of a secondary data source. At the time of data collection ethical approval for all the ELSA waves was granted from the National Research and Ethics Committee. Informed consent was gained from all participants.

\section{Assessment of dependent variable}

In each wave, ELSA respondents were asked, have you ever had cataract surgery? In Wave 1, this variable was used to identify individuals entering the studying having already undergone cataract treatment. The data from subsequent waves was used to identify those having received treatment during the 8-year observation window of ELSA.

\section{Exclusionary criteria}

First, a set of exclusionary criteria were used to ensure that the analysis took into account the probability of cataract surgery uptake given that a respondent was eligible for surgery (i.e. they had cataracts), in order that uptake rates can be disentangled from differential prevalence rates $[12,14]$. Of the initial sample of 11,391 core respondents, 3159 respondents either reported having cataracts on entry to the study $(\mathrm{N}=1543)$ or reported a new diagnosis in waves 2 to $5(\mathrm{~N}=1616)$. Second, respondents were excluded if they entered the study having already had cataract surgery, i.e. the event being examined had already occurred $(\mathrm{N}=784)$. It was also necessary for respondents to be observed at wave 2 , which excluded a further 284 respondents. The final sample comprised of 2091 respondents who were diagnosed with cataracts prior to or during the study, had not undergone cataracts surgery prior to the first survey observation, and had also provided a response in the second wave of the study.

\section{Assessment of economic circumstances}

Wealth at baseline was used as an objective measure of respondents' economic circumstances. Income was not suitable as only a small proportion of people over the age of 65 are in employment and income predictably decreases substantially once individuals retire and leave the labour market [15-17]. On the other hand, wealth is argued to reflect older peoples' life-time cumulative social status and indicates command over material resources better than any other measure of socioeconomic status in later life $[18,19]$. Wealth is measured in net total nonpension wealth at benefit unit (household) level, which includes the value of the primary house minus the outstanding primary house mortgage, the value of savings and shares minus credit card debts and loans, and the value of other properties and businesses. Wealth was entered into the model as quintiles with the highest wealth quintile as the reference group.

\section{Assessment of other covariates}

Increasing age is not only associated with the presence of cataract, but also with the severity of visual impairment from cataract. To control for the non-linear effect of age, age groups were entered into the model. Respondents were grouped into 10-year bands according to age at wave 1 (Age 50-59, 60-69, 70-79, and 80 and over); for interpretation is should be noted that those in the cohort '50-59 years at wave 1' were aged 58-67 in wave 5. The youngest cohort was used as the reference category. Gender was not anticipated to be a significant factor in the uptake of cataract surgery in England, unlike in middle and low-income countries [20], but is nevertheless included in the analysis for the sake of completeness. Ethnicity (white, other) was also entered in the models.

While in England there is a universal free health service on which cataract surgery is available, over $12 \%$ of the population is covered by voluntary health insurance 
schemes, known in the UK as private medical insurance (PMI) [21]. The decision to buy PMI is linked with income [22] and, in the US, type and level of insurance has been shown to be associated with differential cataract surgery uptake rates [23-26]. Although potentially related to wealth, the effects of PMI on uptake of cataract surgery were controlled for by entering a binary variable into the models (no private insurance, private insurance).

To control for the effects of geographical variation and neighbourhood deprivation on access to care [11], the Index of Multiple Deprivation (IMD) was used, which is a measure based on distinct dimensions of deprivation that can be measured separately at the small-area level. Seven dimensions of deprivation are included: income deprivation; employment deprivation; health deprivation and disability; education, skills, and training deprivation; barriers to housing and services; living environment deprivation; and crime. IMD was entered into the models as quintiles with the least deprived quintile as the reference group.

The effects of respondent's self-reported baseline (preoperative) visual function were controlled for (Excellent, very good, good, fair, poor or blind) [27] and furthermore the effects of a recommendation for surgery from a medical professional (no recommendation, recommended, recommendation not known). Respondents were only questioned about recommendation for cataract surgery in waves 2 and 5 ; there were a notable proportion of respondents with a response of 'item not applicable' or with missing data, which together have been categorised as 'recommendation not known'.

\section{Data analysis}

Survival analysis techniques were performed using Stata, version 12.1. All analyses were conducted using wave 2 weights adjusting for survey non-response (all respondents had wave 2 weights but did not necessarily participate beyond this point). When using the stset command in Stata to indicate the format of the data, the enter(time exp) option was used to define when a subject came under observation for the uptake of cataract surgery; i.e. when they had received a cataract diagnosis and were therefore at risk of, or eligible for, treatment. Respondents with a diagnosis prior to the start of the survey $(\mathrm{N}=565)$ were eligible for surgery throughout the 8-year study period while respondents receiving a new diagnosis during the study $(\mathrm{N}=1526)$ would only be eligible from the point of diagnosis.

First, life tables were calculated using Kaplan-Meier estimates to describe the distribution of cataract surgery uptake over time. All respondents were considered eligible for surgery from the point of diagnosis of cataracts until the occurrence of surgery was reported, a censoring event, or the final wave of the study. Kaplan-Meier failure
Table 1 Sample characteristics and incidence of surgery

\begin{tabular}{|c|c|c|c|c|}
\hline & \multicolumn{2}{|c|}{ Baseline/totals } & \multicolumn{2}{|c|}{$\begin{array}{c}\text { Underwent } \\
\text { cataract surgery }\end{array}$} \\
\hline & $\mathrm{N}$ & Weighted \% & $\mathrm{N}$ & Weighted \% \\
\hline \multicolumn{5}{|l|}{ Gender } \\
\hline Male & 751 & 35.8 & 280 & 36.9 \\
\hline Female & 1,340 & 64.2 & 460 & 35.3 \\
\hline \multicolumn{5}{|l|}{ Age group } \\
\hline $50-59$ & 307 & 14.8 & 72 & 23.6 \\
\hline $60-69$ & 689 & 30.8 & 227 & 33.5 \\
\hline $70-79$ & 771 & 37.5 & 302 & 39.7 \\
\hline 80 and over & 324 & 16.8 & 139 & 42.3 \\
\hline \multicolumn{5}{|l|}{ Ethnicity } \\
\hline Non-white & 50 & 3.1 & 21 & 39.9 \\
\hline White & 2,041 & 96.9 & 719 & 35.7 \\
\hline \multicolumn{5}{|l|}{ Wealth quintile } \\
\hline Highest & 441 & 19.8 & 168 & 38.5 \\
\hline Fourth & 390 & 18.0 & 122 & 31.0 \\
\hline Middle & 424 & 20.3 & 154 & 37.2 \\
\hline Second & 407 & 19.7 & 133 & 32.1 \\
\hline Lowest & 409 & 21.2 & 160 & 40.7 \\
\hline Missing & 20 & 1.0 & 3 & 16.2 \\
\hline \multicolumn{5}{|l|}{ Private health insurance } \\
\hline No & 1,881 & 90.3 & 650 & 35.0 \\
\hline Yes & 210 & 9.7 & 90 & 43.5 \\
\hline \multicolumn{5}{|c|}{ Index of multiple deprivation } \\
\hline Least deprived & 461 & 21.2 & 171 & 37.1 \\
\hline Second & 521 & 24.0 & 176 & 34.8 \\
\hline Middle & 439 & 21.1 & 152 & 34.6 \\
\hline Fourth & 372 & 18.5 & 128 & 35.7 \\
\hline Most deprived & 298 & 15.2 & 113 & 37.8 \\
\hline \multicolumn{5}{|l|}{ Self-reported vision } \\
\hline Excellent & 209 & 9.7 & 69 & 32.8 \\
\hline Very good & 546 & 25.5 & 166 & 30.9 \\
\hline Good & 872 & 41.3 & 293 & 34.1 \\
\hline Fair & 344 & 17.1 & 151 & 43.8 \\
\hline Poor or blind & 120 & 6.4 & 61 & 50.6 \\
\hline \multicolumn{5}{|l|}{ Treatment recommended } \\
\hline No recommendation & 386 & 18.30 & 49 & 13.1 \\
\hline Recommended & 368 & 18.10 & 237 & 64.4 \\
\hline Not known & 1,337 & 63.60 & 454 & 34.3 \\
\hline
\end{tabular}

function curves were examined to make univariate comparisons of discrete groups of respondents for all of the categorical predictors. Cox regression-based tests were then performed as a statistical evaluation for the equality of survival curves and as an indicator of the suitability of 
each variable for inclusion in subsequent models (rather than using logrank tests as data were weighted); predictors were considered for inclusion if the test had a p-value of 0.25 or less. This univariate analysis was supplemented by basic descriptive statistics to examine the distribution of the outcome variable among all respondents.

Second, Cox proportional hazards models were used to analyse the effect of wealth on the uptake of cataract surgery, while controlling for the effects of a number of other potentially significant risk factors. Starting with a null model, predictors were entered incrementally into the model; nested models were compared using likelihood ratio tests to assess to overall contribution of the newly entered set of variables.

\section{Results}

During the 8-year follow up period, of the 2091 respondents, 740 reported a diagnosis of cataracts and subsequently underwent cataract surgery (34.9\%); 1407 respondents $(65.5 \%)$ were diagnosed with cataracts prior to or during the study but did not undergo cataract surgery, with 902 not receiving treatment during the study, and 449 leaving the study without first having reported treatment (Tables 1 and 2). Table 2 shows the flow of respondents into and out of the analysis. In the interval between waves 1 and 2, 1015 were eligible for surgery and 220 received treatment; there was a net loss of -215 respondents as 167 respondents did not proceed in the study beyond this point and 382 respondents were added following a newly reported cataract diagnosis. The data for the periods between waves 2 and 3, 3 and 4 and 4 and 5 can be read in a similar way. The overall probability of undergoing cataract removal was 0.557 (Table 2).

Performing basic descriptive statistics (Table 1) and plotting Kaplan-Meier uptake (failure) function by each of the categorical predictors (Figure 1) suggest that there is no discernible relationship between respondents' level of wealth and treatment uptake; the lowest wealth quintile were the most likely to undergo cataract removal (40.7\%), followed by the middle, highest, second, then fourth quintile. On the other hand, age, ethnicity, private insurance, preoperative vision, and receiving a recommendation for treatment appeared to be related to the uptake of treatment. As age at baseline increased, so the probability of undergoing cataract surgery increased. Ethnicity appeared to have an effect of treatment uptake with non-white respondents being more likely to undergo surgery compared with white respondents. Private medical insurance appeared to influence the likeliness of cataract surgery with $35.0 \%$ of those without insurance having cataract surgery and $43.5 \%$ with private insurance undergoing surgery. As baseline visual impairment increases so the probability of undergoing cataract surgery increases. Finally, receiving a recommendation from a medical professional for cataract removal increases the probability of surgery uptake whereas having cataracts, but having no recommendation for a health profession reduces the likeliness of proceeding with cataract removal (64.4\% and $13.1 \%$ respectively).

Multivariate Cox proportional hazard models were used to estimate independent associations between wealth and the uptake of cataract surgery, controlling for the effects of potentially confounding variables. Cox regression-based tests for equality of survival curves indicated that all variables were suitable for inclusion in Cox proportional hazards models with the exception of IMD, which was unlikely to contribute anything to the final mode $(\mathrm{p}=.715)$, and was therefore not included (Table 3). Model 0 was the null model. Model 1 included wealth alone. Demographic variables were then entered into model 2 (gender, ethnicity, age), then other economic factors into model 3 (private insurance) and, finally, medically-relevant factors into model 4 (self-reported vision and professional recommendation). Likelihood ratio tests comparing nested models showed that each set of newly entered variables made a significant contribution to the overall explanatory power of the model. Wealth was dropped from model 5 and likelihood ratio tests comparing model 5 nested within model 4 indicated that having controlled for the effects of all other variables, wealth was not a significant contribution to the overall fit of the model ( $\mathrm{LR} \mathrm{chi}{ }^{2}=10.54, \mathrm{p}=0.061$ ).

Likelihood ratio tests comparing nested Cox proportional hazard models indicated that the inclusion of wealth in the model increased the explanatory power of the model, compared to the null model (LR chi2 $=164.11$, $\mathrm{p}<0.000$ ); however, when entered as the final variable in the model it did not offer a significant contribution $\left(\mathrm{LR} \mathrm{chi}^{2}=10.54, \mathrm{p}=0.061\right)$. The coefficients for wealth did not reveal an informative pattern and none were statistically significant (in either model 1 or model 4). Furthermore,

Table 2 Life table of cataract surgery uptake

\begin{tabular}{lcccccccc}
\hline Time & Interval & Beg. total & Uptake & Net lost & $\begin{array}{c}\text { Uptake (failure) } \\
\text { Function weighted }\end{array}$ & $\begin{array}{c}\text { Uptake (failure) } \\
\text { Function unweighted }\end{array}$ & [95\% & Conf. Int.] \\
\hline 1 & {$[1,2)$} & 1015 & 220 & -215 & 0.230 & 0.217 & 0.193 & 0.243 \\
2 & {$[2,3)$} & 1010 & 165 & -178 & 0.358 & 0.345 & 0.318 \\
3 & {$[3,4)$} & 1023 & 182 & -234 & 0.471 & 0.461 & 0.373 \\
4 & {$[4,5)$} & 1075 & 173 & 902 & 0.557 & 0.548 & 0.434 & 0.4822 \\
\hline
\end{tabular}




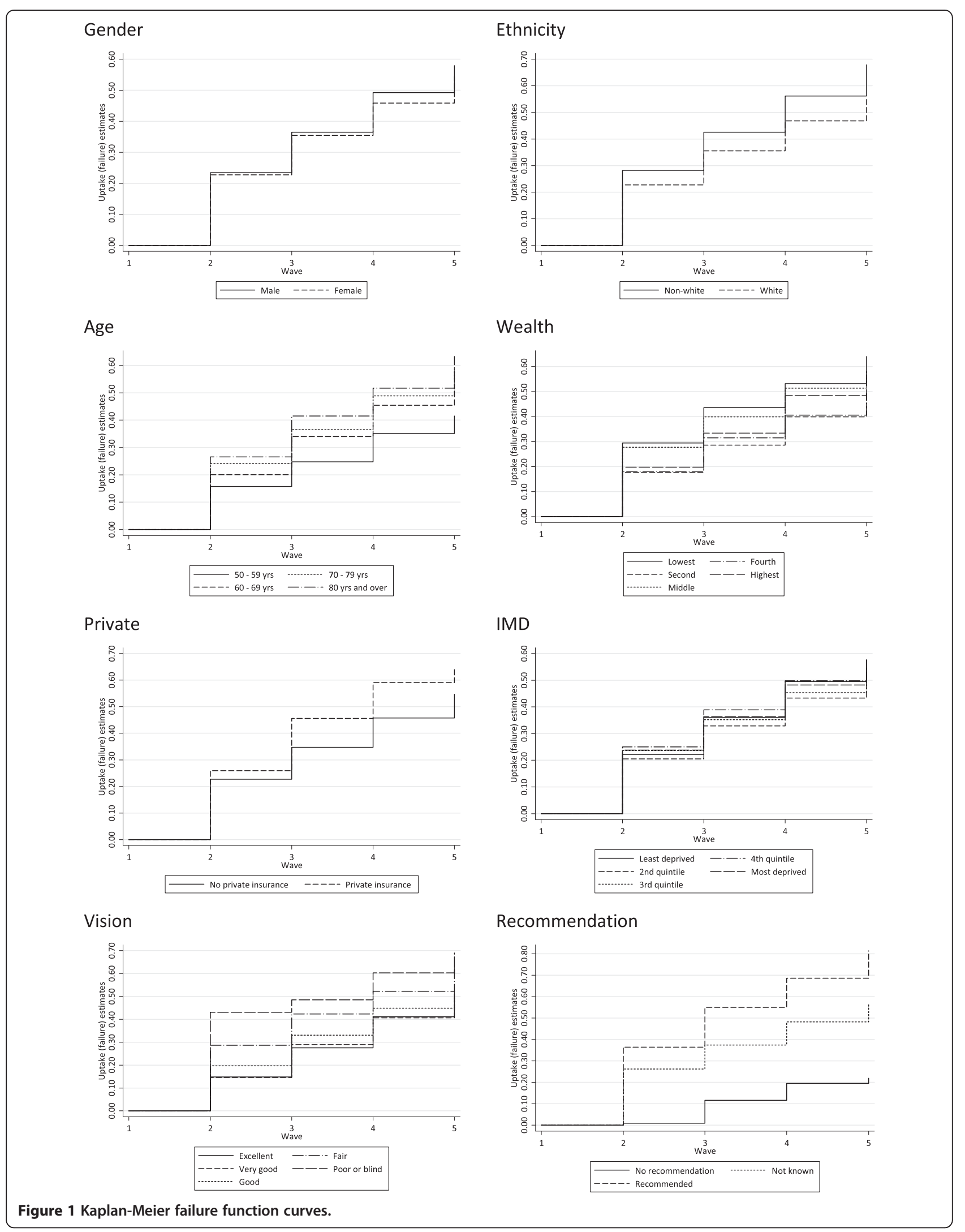


Table 3 Cox regression-based tests for equality of survival curves

\begin{tabular}{lcc}
\hline & Wald Chi-Square & P-value \\
\hline Gender & 1.59 & 0.208 \\
Age group & 19.84 & 0.000 \\
Ethnicity & 1.57 & 0.211 \\
Wealth & 18.36 & 0.003 \\
Private insurance & 5.70 & 0.017 \\
IMD & 2.12 & 0.715 \\
Self-reported vision & 22.83 & 0.000 \\
Recommendation & 181.22 & 0.000 \\
\hline
\end{tabular}

gender and ethnicity were not found to be a significant factor in the uptake of cataract surgery, having controlled for the effects of other variables (Table 4).

On the other hand, age was a significant factor in the uptake of cataract surgery and with increasing age. A gradient in hazard ratio was seen in the effect of self-reported vision at baseline (preoperative) on the uptake of cataract surgery; however, only the effect of self-reporting poor vision of blindness at baseline had a significant effect on the uptake of treatment $(\mathrm{HR}=1.457, \mathrm{p}=0.028)$. Receiving a recommendation for cataract surgery by a medical professional significantly increased the likeliness of undergoing treatment $(\mathrm{HR}=5.490, \mathrm{p}<0.000)$.

\section{Discussion}

The study findings suggest that there is no clear relationship between respondents' wealth and the uptake of cataract surgery among over 50 s with a cataract diagnosis in England. Descriptive statistics showed that the lowest wealth quintile were the most likely to undergo cataract surgery, but Cox proportional hazards models indicated that this was not statistically significant having controlled for the effects of other variables. Increasing age and having self-reported poor preoperative vision were related to undergoing treatment but receiving a recommendation for treatment from a medical professional was a particularly strong influencing factor in the uptake of surgery $(\mathrm{HR}=5.490)$.

The pathway to cataract surgery under the NHS begins with a diagnosis and subsequent referral for surgery initiated either by an optometrist or general practitioner (GP), offering a clear explanation of the magnitude and significance of this variable. However, there is a possible wealth effect on, first, receiving a diagnosis (and therefore for inclusion in the study sample) and, second, on the receipt of a recommendation for surgery [9,28]. Older people in lower income brackets are the least likely to attend NHS-funded eye examinations where identification of eye disease and diagnosis of cataracts are made (citing the potential subsequent cost of glasses as a barrier) [29]. Once in attendance of health services, Dixon et al [7] suggest that by virtue of their education, articulacy, and general selfconfidence, the better off may be better at persuading healthcare professionals that their needs can only be met through specialist services and intervention. While the present study does not reveal significant wealth inequalities in uptake of cataract surgery among those eligible, wealth inequalities may exist further upstream in the process [6,7]. Thus while recipients of NHS cataract treatment do not face fee-for-service charges, individual-level socioeconomic factors may still (indirectly) shape treatment uptake.

The use of private health care by those who can afford it may distort utilisation rates where data are available

\section{Table 4 Cox proportional hazard model}

\begin{tabular}{|c|c|c|c|}
\hline & HR & $95 \% \mathrm{Cl}$ & $\mathbf{P}$ \\
\hline \multicolumn{4}{|l|}{ Gender } \\
\hline Male & 1 & & \\
\hline Female & 0.879 & $(0.768-1.007)$ & 0.063 \\
\hline \multicolumn{4}{|l|}{ Ethnicity } \\
\hline Non-white & 1 & & . \\
\hline White & 0.941 & $(0.587-1.510)$ & 0.802 \\
\hline \multicolumn{4}{|l|}{ Age group } \\
\hline $50-59$ & 1 & & \\
\hline $60-69$ & 1.476 & $(1.155-1.885)$ & 0.002 \\
\hline $70-79$ & 1.599 & $(1.257-2.034)$ & 0.000 \\
\hline 80 and over & 1.750 & $(1.343-2.281)$ & 0.000 \\
\hline \multicolumn{4}{|l|}{ Wealth } \\
\hline Highest & 1 & & . \\
\hline Fourth & 0.868 & $(0.696-1.081)$ & 0.206 \\
\hline Middle & 1.053 & $(0.866-1.281)$ & 0.602 \\
\hline Second & 0.860 & $(0.698-1.059)$ & 0.156 \\
\hline Lowest & 1.132 & $(0.922-1.389)$ & 0.236 \\
\hline Missing & 0.482 & $(0.160-1.450)$ & 0.194 \\
\hline \multicolumn{4}{|l|}{ Private } \\
\hline No private insurance & 1 & & . \\
\hline Private insurance & 1.213 & $(0.991-1.484)$ & 0.061 \\
\hline \multicolumn{4}{|l|}{ Self-reported vision } \\
\hline Excellent & 1 & & \\
\hline Very good & 0.920 & $(0.710-1.192)$ & 0.529 \\
\hline Good & 1.007 & $(0.787-1.289)$ & 0.957 \\
\hline Fair & 1.229 & $(0.932-1.621)$ & 0.143 \\
\hline Poor & 1.457 & $(1.041-2.040)$ & 0.028 \\
\hline \multicolumn{4}{|l|}{ Treatment recommended } \\
\hline No recommendation & 1 & & \\
\hline Recommended & 5.490 & $(4.110-7.333)$ & 0.000 \\
\hline Not known & 3.533 & $(2.639-4.730)$ & 0.000 \\
\hline
\end{tabular}


for NHS care only [6]; the absence of data from the private sector in Keenan et al. may partly explain the socioeconomic gradient observed [11] and has also been raised as a major limitation in the study by Judge et al [10] who examine equity in access to joint replacement in England. ELSA is not restricted to surveying publically-funded care but also includes surgery conducted in the private sector, making this a distinct strength of this study. Private Medical Insurance (PMI) was entered as a variable in the models and while it made a significant contribution to the overall fit of the model, the test of the individual parameter itself was not significant (at $\mathrm{p}<.05)$. By comparison, in the United States where there is a patchwork of public and private health insurance across the population, inequality in access to care leads to differential cataract surgical uptake [24-26]. This may be because publically funded Medicare insurance to cover cataract surgery still entails a financial burden on the individual in the form of deductibles, co-payments, and charges not covered; as such, a beneficiary's income was associated with the odds of undergoing cataract surgery, suggesting an unequal access to care due to financial barriers [23]. A key concern not addressed by this paper is the timing of treatment and the time elapsed between cataract diagnosis and surgery. Notwithstanding the reduction in waiting times for cataract surgery on the NHS between 1997 and 2007 [30], it is highly likely that while these factors are not associated with uptake of treatment (i.e. whether or not surgery occurs), patients in some Primary Care Trusts and those with PMI (and the financial means to pay for this cover) will likely have shorter waiting times. ELSA does not contain information on the date of diagnosis nor the date of treatment; with 2-year intervals between waves of data collection, an analysis of waiting times using ELSA is rather imprecise, although an analysis of this kind would be a valuable next step. In conclusion, these study findings reassuringly suggest that in England, the absence of a fee-for-service charge on the NHS appears to remove financial barriers to the uptake of treatment and recommendation for treatment (which will necessarily be related to preoperative vision) is the driving factor; however, wealth effects may exist in diagnosis of cataracts (a precursor to treatment) and in waiting times leading to treatment, by virtue of differences experienced under public and private care.

\section{Conclusion}

The study findings suggest that uptake of cataract surgery among over 50s with a cataract diagnosis in England do not discriminate on the grounds of individuals' material social position (wealth). Further research is required into whether there is a wealth effect on, first, receiving a diagnosis and, second, on the receipt of a recommendation for surgery which may indirectly lead to wealth inequalities.

\section{Competing interests}

This study was funded by the Thomas Pocklington Trust, a UK registered charity providing housing and support for people with sight loss. The funder has provided financial support but has had no role in data collection, analysis, interpretation of data, or in authoring the manuscript. To this extent, the authors are independent from the funders. The authors declare that they have no competing interests that could appear to have influenced the submitted work.

\section{Authors' contributions}

JW participated in the design of the study, performed the statistical analysis, and drafted the manuscript. JN conceived of the study, participated in its design, and provided revisions to the manuscript. Both authors read and approved the final manuscript.

\section{Acknowledgements}

JW was funded by a research grant from the Thomas Pocklington Trust, a UK based charity providing of housing and support services for people with sight loss.

Received: 15 January 2014 Accepted: 8 September 2014 Published: 30 September 2014

\section{References}

1. Asbell P, Dualan I, Mindel J, Brocks D, Ahmad M, Epstein S: Age-related cataract. Lancet 2005, 365(9459):599-609.

2. The Royal College of Ophthamologists: Cataract surgery guidelines. 2010, http://www.rcophth.ac.uk/page.asp?section=451.

3. Lai F, Lok J, Chow P, Young A: Clinical outcomes of cataract surgery in very elderly adults. J Am Geriatr Soc 2014, 62(1):165-170.

4. Syam P, Eleftheriadis H, Casswell A, Brittain G, McLeod B, Liu C: Clinical outcome following cataract surgery in very elderly patients. Eye 2004, 18(1):59-62. 0000 .

5. Taylor H: Cataract: how much surgery do we have to do? $\mathrm{Br} J$ Ophthalmol 2000, 84(1):1-2.

6. Goddard M, Smith P: Equity of access to health care services: theory and evidence from the UK. Soc Sci Med 2001, 53(9):1149-1162.

7. Dixon A, Le Grand J, Henderson J, Murray R, Poteliakhoff E: Is the British National Health Service equitable? the evidence on socioeconomic differences in utilization. J Health Serv Res Policy 2007, 12(2):104-109.

8. van Doorslaer E, Masseria C, Koolman X, Group ftOHER: Inequalities in access to medical care by income in developed countries. Can Med Assoc J 2006, 174(2):177-183.

9. Allin S, Masseria C, Mossialos E: Equity in health care use among older people in the UK: an analysis of panel data. Appl Econ 2010 43(18):2229-2239.

10. Judge A, Welton NJ, Sandhu J, Ben-Shlomo Y: Equity in access to total joint replacement of the hip and knee in England: cross sectional study. BMJ 2010, 341:C4092.

11. Keenan T, Rosen P, Yeates D, Goldacre M: Time trends and geographical variation in cataract surgery rates in England: study of surgical workload. Br J Ophthalmol 2007, 91(7):901-904.

12. Sparrow J: Cataract surgical rates: is there overprovision in certain areas? Br J Ophthalmol 2007, 91(7):852-853.

13. Steptoe A, Breeze E, Banks J, Nazroo J: Cohort profile: the English Longitudinal Study of Ageing (ELSA). Int J Epidemiol 2013, 42(6):1640-1648. doi:10.1093/ije/dys168.

14. French D, Margo C, Campbell R: Cataract surgery among veterans 65 years of age and older: Analysis of National Veterans Health Administration Databases. Am J Med Qual 2010, 25(2):143-148.

15. French D, Browning C, Kendig H, Luszcz M, Saito Y, Sargent-Cox K, Anstey K: A simple measure with complex determinants: investigation of the correlates of self-rated health in older men and women from three continents. BMC Public Health 2012, 12(1):649.

16. Grundy E, Sloggett A: Health inequalities in the older population: the role of personal capital, social resources and socio-economic circumstances. Soc Sci Med 2003, 56(5):935-947.

17. Grundy E, Holt G: The socioeconomic status of older adults: how should we measure it in studies of health inequalities? J Epidemiol Community Health 2001, 55(12):895-904.

18. de Oliveira C, Shankar A, Kumari M, Nunn S, Steptoe A: Health Risk and Health Protective Biological Measures in Later Life. In Financial 
Circumstances, Health and Well-Being of the Older Population in England: The 2008 English Longitudinal Study of Ageing (Wave 4). Edited by Banks J, Lessof C, Nazroo J, Rogers N, Stafford M, Steptoe A. London: Intitute for Fiscal Studies; 2010:275-347.

19. Demakakos P, Nazroo J, Breeze E, Marmot M: Socioeconomic status and health: the role of subjective social status. Soc Sci Med 2008, 67(2):330.

20. Lewallen S, Mousa A, Bassett $K$, Courtright P: Cataract surgical coverage remains lower in women. Br J Ophthalmol 2009, 93(3):295-298.

21. Boyle S: United Kingdom (England): health system review. Health Syst Transit 2011, 13(1):1.

22. Propper C: The demand for private health care in the UK. J Health Econ 2000, 19(6):855-876.

23. Javitt J, Kendix M, Tielsch J, Steinwachs D, Schein O, Kolb M, Steinberg E: Geographic variation in utilization of cataract surgery. Med Care 1995, 33(1):90-105.

24. Goldzweig C, Mittman B, Carter G, Donyo T, Brook R, Lee P, Mangione C: Variations in cataract extraction rates in Medicare prepaid and fee-for-service settings. JAMA 1997, 277(22):1765-1768.

25. Abraham A, Condon N, Gower E: The new epidemiology of cataract. Ophthalmol Clin North Am 2006, 19(4):415-425.

26. Williams A, Sloan FA, Lee PP: Longitudinal rates of cataract surgery. Arch Ophthalmol 2006, 124(9):1308-1314.

27. Black N, Browne J, Van Der Meulen J, Jamieson L, Copley L, Lewsey J: Is there overutilisation of cataract surgery in England? Br J Ophthalmol 2009, 93(1):13-17.

28. Allin S, Grignon M, Le Grand J: Subjective unmet need and utilization of health care services in Canada: what are the equity implications? Soc SCi Med 2010, 70(3):465-472

29. Conway L, McLaughlan B: Older People and Eye Tests: Campaign Report, Don't let age rob you of your sight. London: RNIB; 2007.

30. Cooper Z, McGuire A, Jones S, Le Grand J: Equity, waiting times, and NHS reforms: retrospective study. BMJ 2009, 339:b3264.

doi:10.1186/1472-6963-14-447

Cite this article as: Whillans and Nazroo: Equal access, (Un)equal uptake: a longitudinal study of cataract surgery uptake in older people in England. BMC Health Services Research 2014 14:447.

\section{Submit your next manuscript to BioMed Central and take full advantage of:}

- Convenient online submission

- Thorough peer review

- No space constraints or color figure charges

- Immediate publication on acceptance

- Inclusion in PubMed, CAS, Scopus and Google Scholar

- Research which is freely available for redistribution 